\title{
School Travel Inequity between Students from Public and Private Schools in the City of Shenzhen, China
}

 \\ ${ }^{1}$ Faculty of Architecture, Harbin Institute of Technology, Shenzhen, China \\ ${ }^{2}$ Shenzhen Key Laboratory of Urban Planning and Simulation Decision, Shenzhen, China \\ ${ }^{3}$ Shenzhen Baoan Institute of Urban Planning and Design, Shenzhen, China \\ Correspondence should be addressed to Yaoyu Lin; 714651073@qq.com
}

Received 3 May 2021; Revised 25 August 2021; Accepted 25 October 2021; Published 18 November 2021

Academic Editor: Mehdi Nourinejad

Copyright (c) 2021 Zuopeng Xiao et al. This is an open access article distributed under the Creative Commons Attribution License, which permits unrestricted use, distribution, and reproduction in any medium, provided the original work is properly cited.

Understanding school travel inequities and promoting active travel policies more effectively is an increasingly important issue in the international transport policy agenda. Using the dataset of the 2014 Shenzhen primary and secondary school travel survey, this study empirically revealed the permanent residence permit (hukou) system in the context of China shapes the evident inequities between students from public schools and private schools. Students without a legitimated hukou to local areas suffer from more constraints, longer distances, and more time to access private schools which are excluded from the public sponsorship and have disadvantages in geographical locations. Applying the ordered logistic model, this study specifically investigated the influential factors of school commuting travel mode. Household vehicle ownership and travel features (i.e., chauffeuring and home-school distance) have a much more significant role in school travel mode decisions, which largely surpassed the role individual demographic attributes and the school surrounding built environment play. The implications of this study shed light on making more specific strategies for private schools to mitigate mobility inequity imposed on disadvantaged students.

\section{Introduction}

The last decades have witnessed the rapid increase of being driven by parents or self-driving from/to schools and a sharp decline of active travel (walking and bicycling) [1-6]. Since active school travel is an important source of physical activities, the increase of motorized school travel has led to a series of adverse results on schoolchildren. These results include but are not limited to children's obesity $[7,8]$, heavy dependence on parental escorts [9], traffic congestion [10], and energy consumption and emissions $[11,12]$. Then, shaping independent, healthy, and active school travel patterns is a critical issue in the current transport policy issue.

Facing this issue, it is essential to look at how school travel mode is socially and spatially determined. Household socioeconomic attributes, intrahousehold interactions, and built environment features were all incorporated as potential determinants [1, 2, 13]. Considering transport mode provision and built environment as important contextual factors, several policy schemes seek to eliminate safety risks along school travel routes [14]. Other options include purchasing or optimizing current school bus services and reviewing and delineating school enrolment areas to reduce long-distance travel [7]. However, whether these policies could equally exert effects of travel choice on students has not been fully taken into account. Evaluating the inequity effects existing in school travel mode and mobility is important to ensure the effectiveness of relevant policy intervention [15].

Several studies increasingly acknowledged the inequities in school travels across schoolchildren subgroups. For example, McDonald [9] and Guliani et al. [16] both revealed the gendered disparities of school travel. Andersson et al. [1] analyzed variations across ethnic groups in Sweden. Moreno-Monroy et al. [17] presented school travel accessibility inequities across students living in areas with different school provisions in São Paulo, Brazil. These studies 
necessitate obtaining insights on the decision of school travel choice across student segments. Consequently, different policy schemes could be implemented on different segments to ensure policies effectively, efficiently, and equally [18].

The objective of this study is to investigate variations on school travel mobility and discuss their implications for making targeted school travel policies to mitigate mobility inequity. The case studied in this research is in the context of China. As socioeconomic development, the automobile rate is rising rapidly in China. The growing motorization at the household level is giving impetus to the increase of schoolchildren being chauffeured to school by parents. Behind the increasing figure, there are evident travel mobility variations existing between schoolchildren from the floating residential households and registered households $[13,19]$. Whether a household is floating or registered legitimately is defined by whether this household has a local urban hukou. In China, the hukou system is a governmental arrangement related to household registration and social resource allotment. With this registered document officially issued by a particular area, it certifies that all household members of this holder are legal residents of this area and could obtain all public services in this particular area. Otherwise, a child cannot be guaranteed the eligibility of being admitted to the local official school. The original intention of the hukou system was to restrict population movement from a rural area and an urban area. This policy currently is facing huge challenges for the massive domestic population movement. The research question is as follows: how do the Chinese hukou-related factors social-spatially shape inequities of schoolchildren's travel mobility? Although this study was contextualized in China, it would rich understandings of the school travel inequities induced by other hukou-like institution contexts.

The remainder of this research is organized as follows. Section 2 provides the literature review and the conceptual framework of this study. The research case, dataset, and variables are presented in section 3. After descriptive analyses in section 4, modeling methods and the empirical results are elaborated in section 5 . The final two sections summarize the research findings and policy implications, with an end of concluding remarks.

\section{Background}

2.1. School Travel Inequity: Review and Framework. Equity issues related to school have been examined for a long time [20]. However, the majority of these studies intended to investigate the equities at the long-term level (e.g., varying educational achievements); fewer attentions have been placed on inequities existing in short-term and everyday school commuting activities. Andersson [1] pointed out that school commuting, as a crucial everyday activity, takes considerable time and would exert significant influences on everyday life (e.g., time use, daily travel) for both children and households. The longer commute time in the morning would certainly reduce sleep time. Further, exhausting school commuting experiences, with less sleep time, are believed to generate more potential risks for students' body and mental health.
Although inequity effects occurring in everyday journey to schools have profound consequences, it has been increasingly recognized only by recent research.

Recent studies have demonstrated the everyday variations on school travel burden and accessibility across different student subgroups [5, 21-25]. For instance, in the case of Sweden in 2000-2006, Andersson et al. [1] found that foreign-born students or students from visible minorities or families with more social assistance have shorter school travel distances. Elias and Katoshevski-Cavari [26] compared the variability in school travel behavior between the Jewish and Arab schoolchildren in Israel and found that Arab children with employed mothers were more likely to be driven to school than to commute by school bus or on foot.

Several groups of factors are confirmed to induce inequities in schoolchildren's travel mobility. The first group of factors includes household socioeconomic status, which defines the quality of social resources and human capital a household could obtain. In addition, no matter which social contexts, the educational system and school enrolment policies are another group of decisive factors that shape travel mobility [1, 13]. Furthermore, these two groups of factors are interactive. Those households with strong social capital probably have sufficient capacities for capturing social opportunities. It would help them obtain priorities in face of the educational system. As shown by the right side of the conceptual framework of this study (Figure 1), this study intends to examine the compulsory education system in China when discussing the school travel inequity in China.

2.2. School Travel Inequity. Besides, contextual effects derived from built environments are increasingly acknowledged as important factors [11, 27-30]. Most studies on school travel mode choice are prone to look at the impacts of neighborhood contexts but neglected the school context [31]. Nevertheless, Mitra and Buliung [23] found that the built environments near home and school locations are both associated with the odds of walking. Broberg and Sarjala [7] displayed that school travel mode choice is more closely associated with the environment en route to a school than with the environment around each home. Consequently, this study is apt to focus on the built environment around school rather than home (Figure 1). Moreover, the school-centered built environment is strongly associated with the school type defined by the compulsory education system, which will be elaborated in detail as follows.

2.3. School Travel Inequity in China. Similar to other countries, China's compulsory education system takes the policy of the school enrolment district as the fundamental arrangement of education resource allotment [13]. The municipal education authority delineates the boundary of enrolment district for each public school. The delineation is based on the spatial distribution of the permanent residential population and the forecasting number of school-age children. Accordingly, a school-aged student whose household hukou is registered in a school enrolment district could legally apply for one study place at this school. Considering the limit of study places in each public school, this hukou- 
based enrolment policy implies children from floating household populations without local hukou could not access local public education resources.

Children who have not obtained a study place from a public school do not have a choice but turn to private schools. There are two kinds of private schools in China. The first one is international schools targeting children from high-income residents. Most of the private schools are the second type which is specified for children from floating households. All private schools in this study refer to the second type. Compared to public schools, private schools do not endow public sponsorship. The tuition fee charged by a private school then is multiple times that in a public school, and the education amenities in a private school generally are not as good as those in a public school. Moreover, there are multifaceted disadvantages to private schools, and these disadvantages probably lead to travel mobility inequities over different schools.

First, to support business operation, private schools do not aim to set a catchment area to enroll more students. It makes the travel distance for students in a private school generally longer than their counterparts in home-nearby public schools. Second, private schools usually are situated in locations without a favorable public transport network, for lacking competitiveness in the land bidding market. On the contrary, public schools are given priority to be located in better places with excellent transport networks. Students from private schools are likely to experience a worse environment to reach their schools [19]. Variations on the school-around built environment are believed to have varying effects on children's mode choice. Students from public schools may have more travel mode options.

The above arguments constitute the conceptual framework of this study as shown in Figure 1. This study aimed to look at the inequities of everyday mobility represented by variations in space-time features of school travels. Demographic variables at the household and individual levels, together with the built environment around the school, are assumed to shape variations on space-time features of school travels. Effects from the determinant of hukou status and school type (public or private) were investigated explicitly in this study. The contextual effects of the built environment around schools are assumed to have significant impacts on school travel features and mode choice. By profiling the interaction effects between influential factors and travel behavior across student groups, policy interventions could be selected and flexibly implemented on the whole groups or specific subgroups. It could contribute to making school travel policy more equitable and efficient.

\section{Research Case and Data}

3.1. Case City. The city of Shenzhen was selected as the case city. Commencing from a special economic zone (SZE) established in the early 1980s, Shenzhen is a metropolitan with a population of 12 million. Shenzhen currently has an administration area of $1,989 \mathrm{~km}^{2}$, covering 10 districts (Figure 2). Four central districts, namely, Luohu, Futian, Nanshan, and Yantian, are located within the original SZE; six peripheral districts are located outside of the original SZE. Although the SZE boundary was officially removed in 2009 , the levels of urbanization and socioeconomic development in the six peripheral districts still largely lag behind their central counterparts. This dualistic space structure resulting from the special SZE policy and development history has exerted profound impacts on the organization of urban daily life and activities. The spatial distribution of schools and school commuting behaviors demonstrate evident disparities between the central and peripheral districts [32].

3.2. Data Collection. The primary dataset was drawn from the 2014 Shenzhen Primary and Secondary School Travel Survey. With official support from the Shenzhen Municipal Education Bureau, this survey was successfully organized by the transport department in the Urban Planning and Land Resource Commission of Shenzhen from June to September 2014. Taking the up-bottom stratified sampling approach, 8 secondary schools and 7 primary schools were first selected. Each school was required to randomly sample one class from each grade to participate in this survey. Students from the selected classes were invited to complete a school travel questionnaire after a tutorial from the instructors. Students younger than 10 years old were asked to bring the questionnaires home, and their parents were invited to help them complete this survey. After excluding invalid and uncompleted questionnaires, there were 5,463 qualified questionnaires, accounting for $83.5 \%$ of all respondents. The collected information included departure time in the morning from home to school, duration, travel distance, mode, chauffeuring/pickup, departure time, and arriving time from school to home. General information, such as household vehicle ownership, student age, and student grade, was gathered at the same time.

Considering afternoon trips home from school may involve other activities, only the morning trips from home to school were investigated in this study. Additionally, because the commuting behaviors of secondary students differ significantly from those of primary students, this study only focused on primary school students. Then, only 7 primary schools were involved in this study (Figure 2). Specifically, five schools are public, and the remaining two are private. Three schools are located in peripheral districts, and the others are in the central districts. Sampling information for each respondent school can be found in Table 1.

Spatial attributes of the built environment within the buffer area of a 500-meter radius around each school were calculated in the geographical information system (GIS) of Shenzhen (Figure 3). These attributes, including road density, the number of street-crossing facilities, the number of street-crossing intervals, and the number of bus stations, would be displayed in the following empirical part after the descriptive analysis. Evident are variations on school-around built environment across seven schools. The public schools have advantages in location and transport network. The schools located in peripheral districts are exposed to environments with more urban villages. 


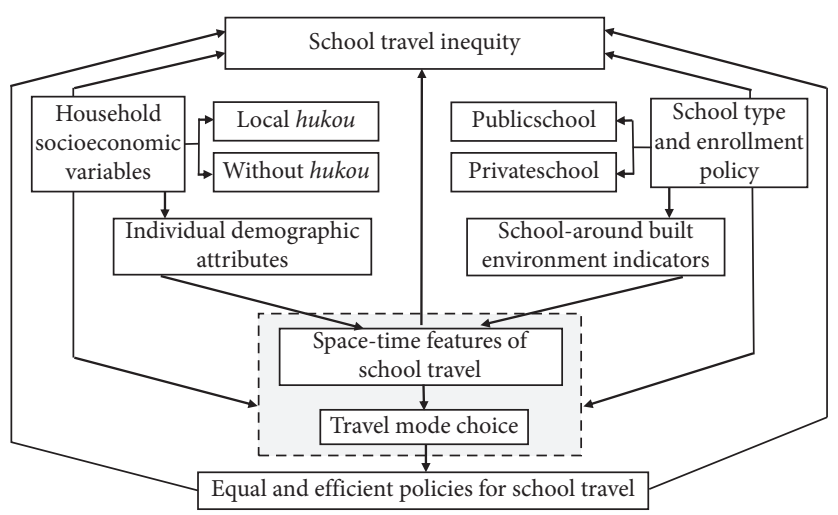

FIGURE 1: Conceptual framework for exploring school travel inequity.

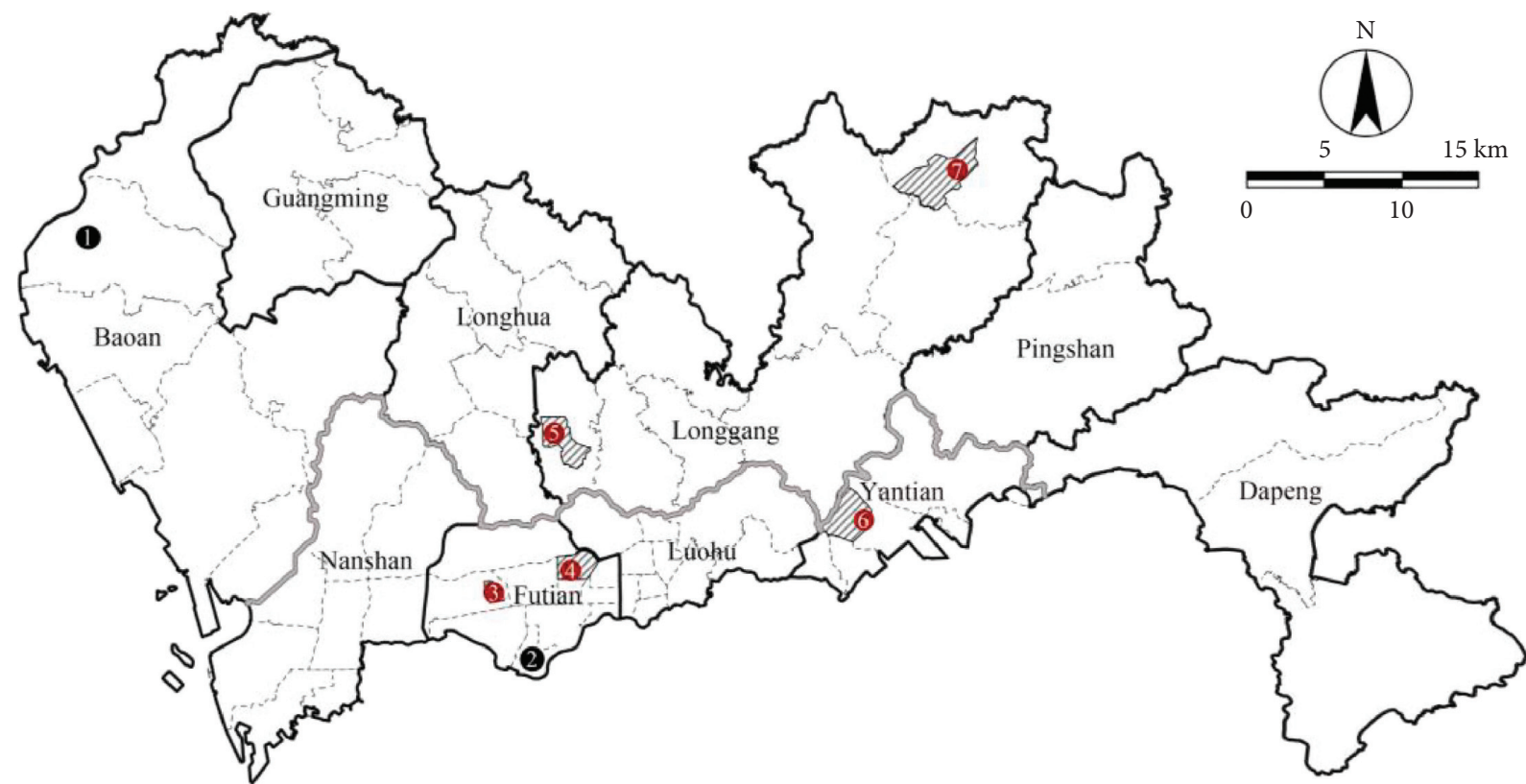

\footnotetext{
2

- - - Subdistrict boundary District boundary

Private School:

(1) Guanqun Primary School

2 Futian Bond Area Primary School
}

- SEZ boundary

Public school:
(3) Liyuan Foreign Language Primary School
6 Bantian Primary School
(4) Huaxin Primary School
(7) Lequn Primary School
5 Pingdi No.1 Primary School

FIgURE 2: The geographical location of school samples.

\section{Descriptive Analysis of School Commuting Inequity}

4.1. Commuting Duration and Distance. According to the statistical results, primary students in Shenzhen left their homes for school at approximately 7:08 am (Table 2). The average travel time and distance of the morning journey from home to school were 21.5 minutes and $2.238 \mathrm{~km}$, respectively. Evident are interschool variations across school types (Figure 4). Students from the public schools averagely traveled less duration (19.16 minutes) and distance $(2.040 \mathrm{~km})$ than those of their counterparts from private schools (25.6 minutes and $3.093 \mathrm{~km}$ ). Specifically, students from the public LY schools took the shortest time (13.5 minutes), which was half 
TABLE 1: Summary for school samples.

\begin{tabular}{|c|c|c|c|c|c|c|}
\hline School type & School name & Abbr. & District & No. of students & No. of qualified samples & $\begin{array}{c}\text { Qualified } \\
\text { sampling rate }\end{array}$ \\
\hline \multirow[t]{2}{*}{ Private } & Guanqun primary school & GQ & Bao'an & 2717 & 388 & 14.28 \\
\hline & Futian bond area primary school & BS & Futian & 880 & 190 & 21.59 \\
\hline \multirow[t]{6}{*}{ Public } & Huaxin primary school & HX & Futian & 970 & 199 & 20.52 \\
\hline & Liyuan foreign language primary school & LY & Futian & 1088 & 193 & 17.74 \\
\hline & Bantian primary school & $\mathrm{BT}$ & Longhua & 1300 & 202 & 15.54 \\
\hline & Pingdi No.1 primary school & $\mathrm{PD}$ & Longgang & 1662 & 251 & 15.10 \\
\hline & Lequn primary school & LQ & Yantian & 1000 & 547 & 54.70 \\
\hline & Total & & & 7767 & 1970 & 25.36 \\
\hline
\end{tabular}

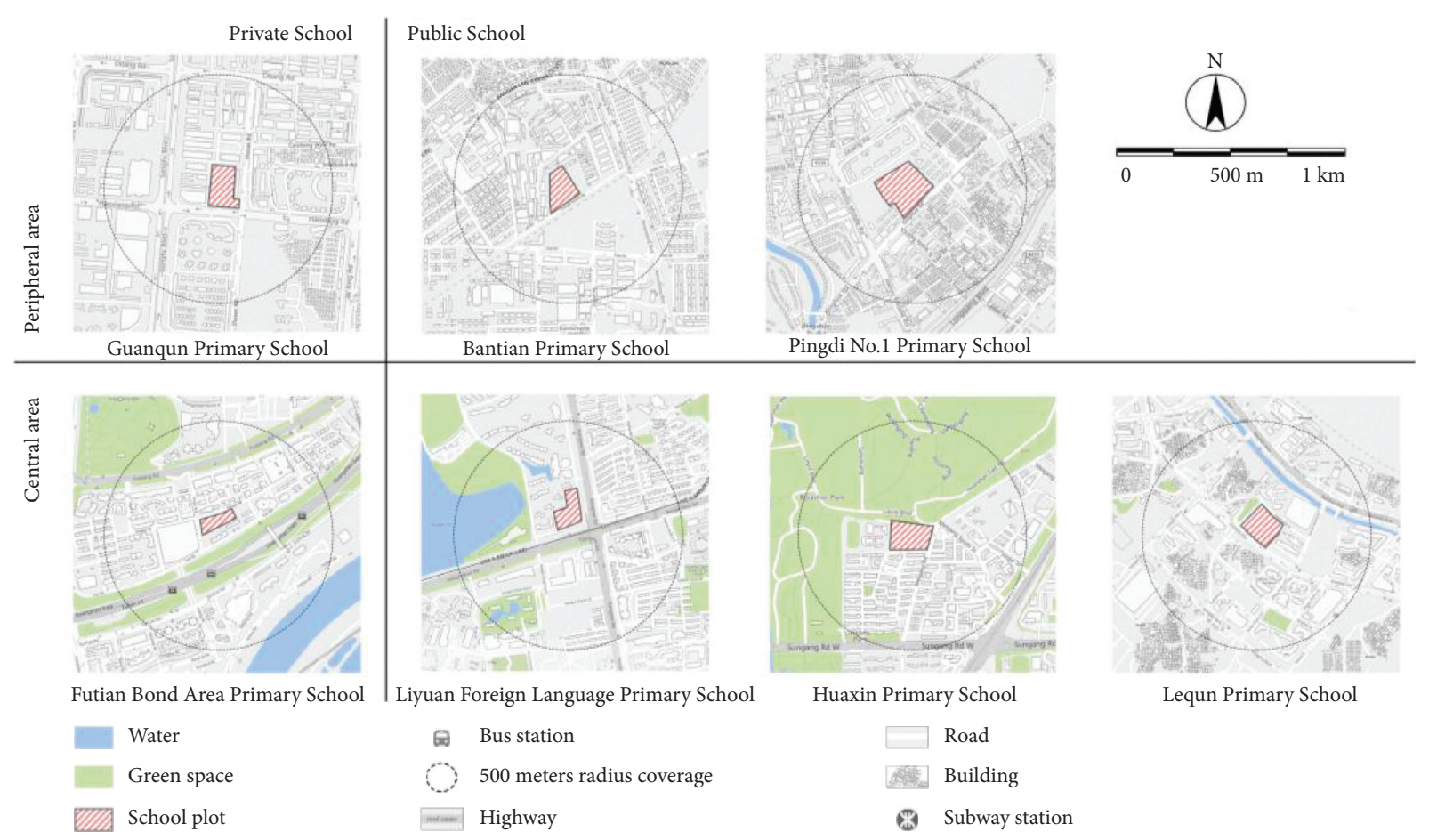

FIGURE 3: School-around built environment.

of that of students from the private GQ school. The latter had the most extended average travel duration (26.776 minutes) and distance $(3.204 \mathrm{~km})$. It implies the interschool variations on student commute mobility again. In addition, Figure 4 also showed the potential variations between schools from the central and peripheral areas, which would be illustrated in the following paragraphs.

4.2. Commuting Distance by Grade. School commuting distance generally increased with grade (Figure 5). However, minor were the intergrade variations on school travel distance for public school students. For private school students, the school commuting distance increased sharply with the grade. Specifically, private school students in grade 6 had the longest average distance, 2.6 times that of grade- 1 students with the shortest commuting distance on average.

The reason for producing the evident variations lies in that private schools do not have a specified enrolment catchment area. With the increase in grade, the capability of independent commuting without parental support increases significantly. Students and parents, therefore, have more spatial flexibility to choose any private school. The school that children are going to study in is not necessarily confined to be near their homes. Some parents even intend to send their children to schools with higher education quality, even though these schools are far from home. It is in line with the case of Beijing reported by $\mathrm{Li}$ and Zhao [13].

4.3. Travel Mode and Escort. Walking was the most common school travel mode, which accounted for around $61.49 \%$ of all respondents (Table 3). Except for this mainstream mode, the proportions of bicycle, public bus, and school bus were all no more than $10 \%$. However, the proportion of commuting by car reached $12 \%$. In particular, the shares of commuting by car in LY, PD, and BS even surpassed the average level of $12 \%$. School students with a higher mode split of cars had a higher rate of parental escort. This result shows that the level of private motorized travel on school commuting increases with the ongoing motorization of household travel mobility. 
TABle 2: Departure time, average travel duration, and distance of school commuting.

\begin{tabular}{lcccc}
\hline School type & Abbr. of the school name & Average departure time & Travel duration (minutes) & Travel distance (km) \\
\hline Private & GQ & $6: 45$ & 26.776 & 3.204 \\
Public & BS & $7: 05$ & 24.379 & 19.644 \\
& BT & $7: 15$ & 18.163 & 1.852 \\
& PD & $7: 27$ & 13.487 & 2.334 \\
& LY & $7: 28$ & 23.427 & 1.905 \\
Mean & HX & $7: 16$ & 21.102 & 2.811 \\
& LQ & $7: 04$ & 2.238 & 1.301 \\
\hline
\end{tabular}

The school commuting mode also showed evident interschool variations. Walking had the highest rate in LQ $(87.93 \%)$, followed by BT $(74.26 \%)$. Although the shares of walking in HX and LY were not as high as those in LQ and BT, HX had the highest rate of taking public buses $(24.62 \%)$ and bicycles (11.56\%, only less than GQ). In contrast, LY had the highest travel proportion of the car $(24.35 \%)$. PD had the lowest walking share $(52.99 \%)$ but had the second-highest proportions for bicycles (11.55\%, less than HX), cars (16.73\%, less than LY), and public transit (8.76\%, less than $\mathrm{HX}$ ) in the group of public schools. Besides, the public PD school, located in the peripheral area, offered school bus services to students; therefore, the school bus accounted for $9.41 \%$ of all travel modes of school commuting in the PD school. In comparison, students from private schools had the lowest rates of walking (53.16\% and $40.46 \%$ ) and had more percentage of taking school buses to schools $(17.37 \%$ in BS and $29.38 \%$ in GQ). GQ had the highest rate of taking a bicycle, while BS in the central area had the second-highest rate of car among all seven schools.

\section{Empirical Analyses of Travel Mode Choice}

5.1. Methods, Variables, and Model Specification. To examine the determinants of school travel mode choices, we developed an empirical econometric model by a multinomial logistic (MNL) approach. This approach has been intensively used in studies on travel mode choices $[7,11,13,15]$. The dependent variable is travel mode, including five options, namely, walk, bicycle, bus, school bus, and car.

As the conceptual framework indicates, four groups of independent variables were incorporated into the empirical analysis (Table 4). The first group refers to socioeconomic variables at the student level, such as gender, grade, and household car ownership. Two travel-related variables, chauffeuring and travel distance, belong to the second group and are also at the student level. The third group of variables includes school-based built environment attributes collected by the GIS-aided instruments. Information for each school initially includes the school catchment area size, road density, street-crossing intervals, public transport/subway accessibility, pedestrian lane, cycling lane, and green park coverage. The final built environment attributes after collinearity tests, including definition, calculation methods, and related hypotheses, are listed in Table 4.

To further identify the impacts of different groups of independent variables, we firstly incorporated socioeconomic variables at the student level and travel-related variables in Model 1. Built environment attributes were then incorporated in Model 2. Both Model 1 and Model 2 had a good fitness level (Table 5), with maximum likelihood values of -1011.635 and -952.584 , respectively. Both Chisquared values were statistically significant at the level of 0.001 .

5.2. Effects of Student-Level Travel Feature Variables. Parents who escorted their children to schools were likely to use bicycles and cars compared to walking, with odd rate coefficients of 1.951 and 2.512, respectively. The inconvenience of taking public transport at the door-to-door level and lacking safety for independent travel is believed to be the primary reasons that parents choose to accompany their children to school [33].

Travel distance is another crucial determinant. The longdistance trip encouraged a more significant probability of using bicycles (2.121), buses (2.813), cars (2.903), and school buses (2.721) compared to walking. Notably, all estimated coefficients were statistically significant at the level of $99 \%$. After incorporating the built environment factors, all coefficients altered slightly. This finding confirms the strong associations between travel distance and travel mode choice. This finding coincides with Kelly and Fu [34] that travel distance to school is the most significant determinant of school travel choice.

5.3. Effects of Student-Level Socioeconomic Attributes. Gender does not have evident effects on travel mode choices as expected. The results only show that boys did not incline to take the bus compared to walking in the case. After incorporating built environment indicators and controlling their contextual effects on travel choices, the impacts of gender on mode decisions did not have evident changes. It fits our expectation that there are no effects of built environments on travel mode choice through gender.

Grade, representing age, could exert impacts on travel mode choices. In Model 1, a student in a higher grade had a higher likelihood of taking a bus (Coef. $=0.287$ ). After incorporating built environment attributes in Model 2, the connection between age and travel mode changed. First, the increase in grade may improve the likelihood of taking school buses, although the coefficient was not significant in statistics. The probability of being chauffeured by their parental vehicles would reduce for students in higher grades 


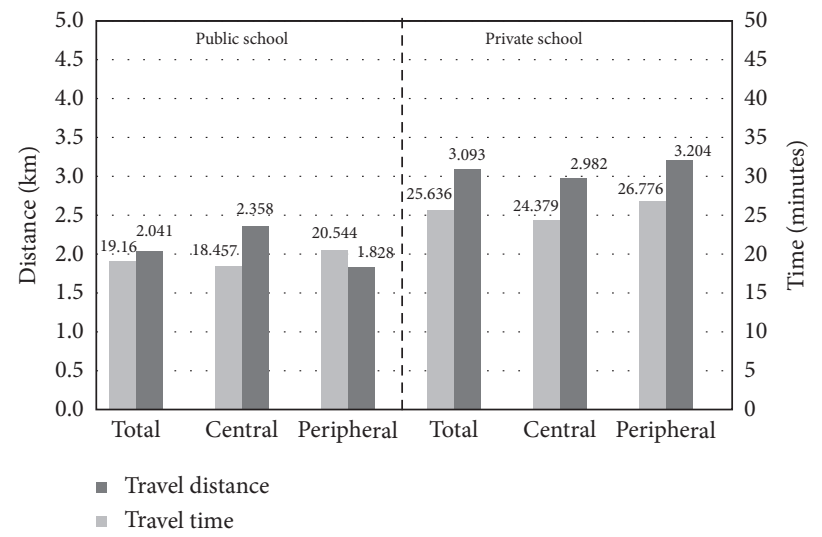

FIGURE 4: School commuting distance and duration by school type.

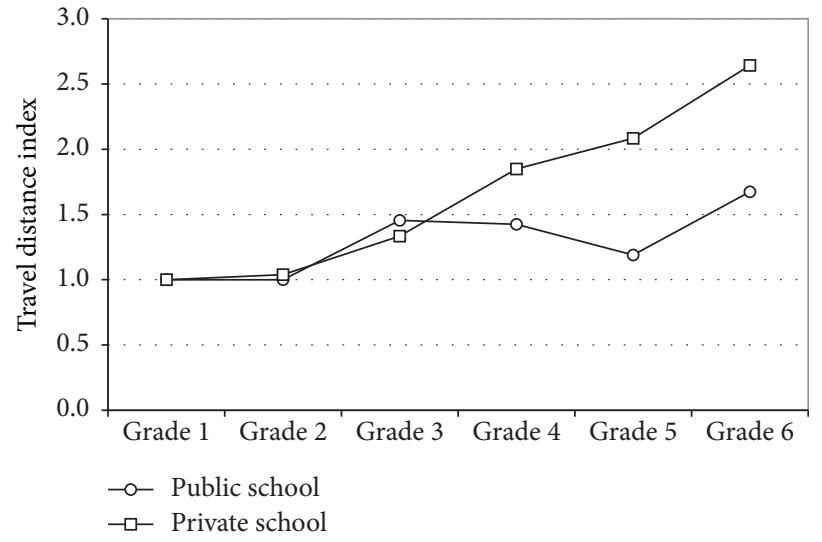

Figure 5: Average school commuting distance by grade.

TABle 3: Average travel mode split and parental escort rate across different schools.

\begin{tabular}{|c|c|c|c|c|c|c|c|}
\hline \multicolumn{2}{|c|}{ School } & \multicolumn{5}{|c|}{ Model split (\%) } & \multirow{2}{*}{$\begin{array}{c}\text { Escort rate } \\
(\%)\end{array}$} \\
\hline $3 \mathrm{ln}$ & & Walk & Bicycle & Public bus & School bus & Car & \\
\hline \multirow{3}{*}{ Private school } & 44.63 & 14.71 & 6.40 & 25.43 & 8.82 & 42.30 & \\
\hline & GQ & 40.46 & 19.59 & 6.19 & 29.38 & 4.38 & 35.86 \\
\hline & BS & 53.16 & 4.74 & 6.84 & 17.37 & 17.89 & 55.44 \\
\hline \multirow{6}{*}{ Public school } & 71.98 & 6.39 & 9.34 & 1.80 & 10.43 & 31.54 & \\
\hline & HX & 54.27 & 11.56 & 24.62 & - & 9.05 & 50.53 \\
\hline & LY & 67.36 & 1.55 & 6.74 & - & 24.35 & 50.50 \\
\hline & $\mathrm{BT}$ & 74.26 & 9.41 & 6.44 & - & 9.41 & 23.45 \\
\hline & $\mathrm{PD}$ & 52.99 & 11.55 & 8.76 & 9.96 & 16.73 & 53.62 \\
\hline & LQ & 87.93 & 2.74 & 6.03 & - & 2.19 & 10.79 \\
\hline Mean & 61.49 & 8.73 & 9.37 & 8.40 & 12.00 & 30.05 & \\
\hline
\end{tabular}

Note: -, no school bus service provided.

$($ Coef. $=-0.315)$. This finding is consistent with the expectation that students are likely to travel independently with the increase of grade and age. The chance of taking bicycles also reduced with students' grades $($ Coef. $=-0.297)$. It may result from an unfriendly cycling environment during the peak morning hours in the case city.

Household car ownership, as a proxy variable of household income level, played a vital role in students' school travel mode decisions. The opportunity of taking a car to school for students from car-owning households was 2.647 times greater than that of their counterparts from noncar-owning households. In addition, this decisive effect was statistically significant at the level of $99 \%$. Accordingly, students from car-owning households did not intend to take bicycles, buses, or school buses, although only the coefficient of family car ownership on the likelihood of taking a bicycle $(-0.554)$ was statistically significant. This finding is in line with studies in other contexts $[32,35,36]$. 
TABLE 4: Variables used in the model.

\begin{tabular}{|c|c|c|}
\hline Variable & Type & Variable description and assumption \\
\hline \multicolumn{3}{|c|}{ Individual demographic variables } \\
\hline Gender & dummy & 0 , girl; 1 , boy. Boys are assumed to prefer motorized modes. \\
\hline Grade & ordinal & Higher-grade students intend to use motorized travel. \\
\hline Vehicle & dummy & 1, household owns $\operatorname{car}(\mathrm{s}) ; 0$, no. Students from car-owning households are likely to be driven to school. \\
\hline \multicolumn{3}{|c|}{ Individual travel features } \\
\hline Escort & dummy & 1 , picked up by parents; 0 , no. Students who are escorted are likely to use a motorized tra \\
\hline Distance & continuous & Longer distance trips lead to more motorized usage. \\
\hline \multicolumn{3}{|c|}{ School-level attribute variables } \\
\hline Public & dummy & $0, \mathrm{p}$ \\
\hline Location & dummy & 0 , peripheral; 1 , central \\
\hline \multicolumn{3}{|c|}{ School-level built environments } \\
\hline Catchment size & continuous & Large size enco \\
\hline Road density & continuous & Higher densit \\
\hline $\begin{array}{l}\text { Street-crossing } \\
\text { facilities }\end{array}$ & continuous & $\begin{array}{l}\text { The number of street-crossing facilities within a school-centric buffer area with a radius of } 2 \mathrm{~km} \text {. More } \\
\text { facilities benefit walking and cycling. }\end{array}$ \\
\hline $\begin{array}{l}\text { Street-crossing } \\
\text { intervals }\end{array}$ & continuous & $\begin{array}{l}\text { The average spacing distance between two nearby street-crossing facilities along all roads within a } \\
\text { school-centric buffer area with a radius of } 2 \mathrm{~km} \text {. A smaller interval facilitates walking and cycling. }\end{array}$ \\
\hline Bus station & continuous & More stations encourage travel by public transit. \\
\hline Subway & dummy & 0 , no subway station within $1 \mathrm{~km}$ of the sampled school; 1 , yes \\
\hline
\end{tabular}

TABle 5: Model results.

\begin{tabular}{|c|c|c|c|c|c|c|c|c|c|}
\hline \multirow{2}{*}{\multicolumn{2}{|c|}{ Variable }} & \multicolumn{4}{|c|}{ Model 1} & \multicolumn{4}{|c|}{ Model 2} \\
\hline & & Bicycle & Bus & Car & $\begin{array}{l}\text { School } \\
\text { bus }\end{array}$ & Bicycle & Bus & Car & School bus \\
\hline \multirow{5}{*}{$\begin{array}{l}\text { Student-level } \\
\text { Demographic }\end{array}$} & Constant & $-4.305^{* * *}$ & $-7.782^{* * *}$ & $-10.982^{* * *}$ & $-6.793^{* * *}$ & -0.097 & 1.876 & 0.624 & $-29.693^{* * *}$ \\
\hline & & & & & & & & & \\
\hline & Gender & -0.223 & $-0.445^{*}$ & -0.413 & -0.376 & -0.251 & $-0.530^{* *}$ & -0.383 & -0.349 \\
\hline & Grade & -0.107 & 0.003 & -0.059 & $0.287^{* *}$ & $-0.297^{* *}$ & -0.163 & $-0.315^{*}$ & 0.054 \\
\hline & Vehicle & $-0.554^{*}$ & -0.138 & $2.647^{* * *}$ & -0.010 & $-0.576^{*}$ & -0.326 & $2.265^{* * *}$ & -0.294 \\
\hline \multirow{2}{*}{ Travel feature } & Escort & $1.951^{* * *}$ & -0.027 & $2.512^{* * *}$ & 0.010 & $1.944^{* * *}$ & -0.069 & $2.187^{* * *}$ & -0.255 \\
\hline & Distance & $2.121^{* *}$ & $2.813^{* * *}$ & $2.903^{* * *}$ & $2.721^{* * *}$ & $2.114^{* * *}$ & $2.870^{* * *}$ & $2.987^{* * *}$ & $2.791^{* * *}$ \\
\hline \multicolumn{10}{|l|}{ School-level } \\
\hline \multirow[t]{2}{*}{ School attribute } & School type & $-0.714^{* *}$ & $0.686^{*}$ & 0.324 & $-2.202^{* * *}$ & & & & \\
\hline & School location & 0.071 & 1.709 & $1.511^{* * *}$ & $0.544^{*}$ & & & & \\
\hline \multirow[t]{6}{*}{$\begin{array}{l}\text { Built } \\
\text { environment }\end{array}$} & Catchment size & & & & & -0.032 & $0.103^{*}$ & $0.076^{*}$ & $0.614^{* * *}$ \\
\hline & $\begin{array}{c}\text { No. of street-crossing } \\
\text { facilities }\end{array}$ & & & & & 0.012 & $-0.038^{*}$ & -0.028 & $0.523^{* * *}$ \\
\hline & $\begin{array}{l}\text { Street-crossing } \\
\text { interval }\end{array}$ & & & & & 0.000 & $-0.004^{* * *}$ & $-0.003^{* * *}$ & $0.011^{* * *}$ \\
\hline & Road density & & & & & $0.170^{*}$ & $-0.247^{* *}$ & $-0.447^{* * *}$ & $0.530 * * *$ \\
\hline & $\begin{array}{l}\text { No. of public bus } \\
\text { stations }\end{array}$ & & & & & $-0.386^{* * *}$ & $-0.450^{* * *}$ & $-0.571^{* * *}$ & $0.614^{* * *}$ \\
\hline & Subway & & & & & $-0.703^{*}$ & $0.582^{*}$ & $1.433^{* *}$ & $-8.548^{* * *}$ \\
\hline & \multirow{2}{*}{$\begin{array}{l}\text { No. of observations } \\
\text { Maximum likelihood } \\
\text { estimate }\end{array}$} & \multicolumn{3}{|c|}{1970} & \multicolumn{5}{|c|}{1970} \\
\hline & & \multicolumn{3}{|c|}{-1011.635} & \multicolumn{5}{|c|}{-952.584} \\
\hline & Chi-square value & \multicolumn{3}{|c|}{2519.19} & \multicolumn{5}{|c|}{2637.29} \\
\hline & $P$ value & \multicolumn{3}{|c|}{0.000} & \multicolumn{5}{|c|}{0.000} \\
\hline & Pseudo $R^{2}$ & \multicolumn{3}{|c|}{0.555} & \multicolumn{5}{|c|}{0.581} \\
\hline
\end{tabular}

1: baseline, walking. 2: $P<0.001,{ }^{* * *} ; P<0.01,{ }^{* *} ; P<0.1,{ }^{*}$.

After considering the effects resulting from the contextual built environment, the effects between car availability and the likelihood of using a car for school travel mode moderately decreased from 2.647 to 2.265 . For students from a car-owning household, the odd rates of taking a bicycle, bus, or school bus in comparison with walking decreased slightly, although not all coefficients are significant in statistics. These results indicate that the built environment has 
little effect on household behaviors of using cars for school travel but could influence the incidence of noncar travel behaviors. This finding coincides with Li and Zhao [13] that students from households with private cars are more likely to be driven to school in China.

5.4. Effects of School-Level Attributes. Regarding school type, compared to walking, students from public schools were less inclined to use bicycles $(-0.714)$ and would like to take a public bus (0.686) and cars (0.324). Private school students had more likelihood of taking a school bus compared to walking. The reason was that both private schools in this study provided bus services. It also indicates the potential substitution effects of offering bus services to students on taking a family vehicle for school commuting.

School location is another factor that affects the choice of travel mode. Students from schools located in the central areas were more likely to take cars to school, with a coefficient of 1.511 that was statistically significant at the level of $99 \%$. School buses were also more acceptable with a coefficient of 0.544 .

5.5. Effects of the School-Around Built Environment. After moving two school-level variables (location and type) and incorporating corresponding built environment indicators, the effects on travel mode choices from the socioeconomic variables at the student level and travel-related features roughly remained consistent with the results of Model 1 that do not include built environment variables. Hence, we could induce that the effects of demographic variables on school travel mode choice are not vulnerable to being affected by the impacts exerted from the built environment. The effects of the built environment on mode choices may not be as strong as expected, consistent with Andersson et al. [1] and McDonald [9].

Schools with larger enrolment areas were likely to have more students who did not live near the school. It increased the likelihood of using public buses $($ Coef. $=0.103)$ and cars (Coef. $=0.076)$.

Higher road density, more street-crossing facilities, and more street-crossing intervals are all expected to encourage the likelihood of using bicycles and taking school buses and reduce the probabilities of using buses and cars, compared to walking. It suggests that the small-block urban form could exert positive effects on noncar usage and encourage active travel modes.

More public bus stations would decrease the likelihood of taking bicycles, buses, and cars compared to walking. The potential reason is that the areas with high public bus accessibility are usually located in the central areas where the schools usually had a favorable walkability environment. The increase of public bus lines conversely would bring more parental concerns on transport safety. The potential substitution effects of providing better public bus service on other travel modes do not work. At the same time, we note that the number of public transit stations is positively associated with the likelihood of using school buses for school commuting. It indicates the usefulness of school buses compared to standard public buses.

It fits our expectation that better access to a subway station could promote the likelihood of taking public buses on school commuting with a coefficient of 0.582 . However, the availability of metro stations could not mitigate the likelihood of taking family vehicles (Coef. $=1.433$ ). Besides, there would be a basis that the marginal odds of access to metro stations on taking a school bus compared to walking were as much as -8.548 . The reason is that two schools in all three schools that provided school bus services were private schools located in peripheral areas currently without nearby subway stations. Hence, in this study, accessing subway stations decreases the rate of using school buses. This casespecific basis should be noted by future studies.

\section{Discussion and Policy Implications}

6.1. Understanding Travel Inequity Associated with Social Contexts. As this research seeks to convey, school travel inequity is important but often neglected issue in the literature available on education and transport inequity [15]. This travel inequity occurs in the everyday mobility of schoolchildren, presented by variations on school travel duration, distance, mode, and escort. Beyond these symbolical variations, school travel inequity is deeply embedded in social group stratification and education resource allotment [1], presenting at different social contextual dimensions. Current research has shown this inequity presented across gender, ethnic groups in the United States, migrant and nonmigrant households in Sweden [37], and income segment in Albania [35].

This study illustrated that school travel inequity in the context of China heavily depends on whether a household holds a permanent residence permit to a local area (i.e., hukou). Specifically, floating workers have contributed labor and taxes to the city in which they live, but their children do not have equal eligibility for engaging the public education service system of the local city for lacking local urban hukou. The hukou-based institution of allocating a series of social opportunities is profoundly shaping the travel inequities between students from local hukou and nonlocal households. In the case of Shenzhen, pupils from non-hukou households must study in private schools, and their travel distance, on average, was 1.67 times that of students from public schools with local hukou. In Beijing, the school equity lies in the interschool gap that the share of taking parental cars to school for students in premium schools was 2 times that of students from ordinary private schools. The shocking multiple-gap even reached as high as 20 times for students from low-income household schools [38].

The inequity effects of hukou-related educational resource arrangement on social segregation are especially evident in the case city where there is a massive number of floating workers and a limited population of residents with a permanent hukou. As for floating worker households, their children, only due to lacking legitimated residence rights to local cities, have to generally suffer from longer school commute duration and distance, more constraints, and less 
flexibility on travel mode options. These unequal situations and cross-generation deprivation should be intensively noticed by education and civic affair authorities to investigate the potential adverse impacts on students' education performance and social mobility.

6.2. Mitigating Travel Inequity and Car Dependence by Subgroup-Targeted Strategies. Studying travel mobility inequity and mode choice across different groups sheds light on making efficient and effective policies dedicated to equalizing travel mobilities and promoting active school travel. McDonald [9] pointed out that the policy interventions of promoting bicycle usages should ensure the female's participation. Guliani et al. [16] also reminded policy-makers of the gendered nature of school travel behavior. Medeiros et al. [15] emphasized the importance of 'subgroup' analysis on assessing the equity effect and improving the utility and applicability of policy intervention. In this study, the focus should be done on how to provide more targeted policies for private schools to mitigate school inequities.

First, it is necessary to build more primary schools, enhance the density, and ensure the enrolment size of each school is within a reasonable range. Moreno-Monroy et al. [17] criticized that the policy proposal of agglomerating primary schools undermined the school accessibility of students from disadvantaged groups. The policy intention in the context of Moreno-Monroy et al. [17] was to expand the student enrolment area to cope with the decreasing number of school-age students. In the current Chinese metropolis, the problem lies in the limit of schools and the oversupply of school-age students. To meet demands, private schools strive to provide more study places to support business operations. Official departments also do not intend to delineate a specific enrolment boundary for each private school. These deficiencies bring about an unintended consequence of increasing the percentage of students with longer school travel distances. Therefore, building more private schools and narrowing the catchment service area for each school can help fundamentally reduce the travel inequities.

Second, as Model 2 empirically implies, increasing street-crossing facilities (crossing guards and overpasses) enhances the friendliness of school-around built environment for walkers and bicyclists. It could further stimulate students to take active modes and discourage parental escort by car. Other infrastructural solutions include signalization, pedestrian-exclusive walkways, and adding pedestrian fencing. The feasibility of these infrastructural policy packages, included in a range of 'school travel plan' practices, has been confirmed in the United States and Australia [14]. These infrastructural policies could be applied firstly to private schools that operated for children from floating households in China. These disadvantaged schools, without public sponsorship, did not have more considerations on the safety risks when the school sites were selected at that time. Therefore, compared to public schools, private schools have greater safety-related risk exposure derived from schoolaround built environment and traffic dangers on school travel routes from home. It coincides with findings in Sallis et al. [39] and Zhu and Lee [40] that higher socioeconomicstatus neighborhoods probably embrace higher quality pedestrian transport infrastructure, such as walkways, pedestrian and biking facilities, and maintenance. Eliminating the safety risks related to the built environment firstly on private schools would attract more participation of shifting to active travel mode alternatives than that on public schools. It would ultimately bring about equity effects for children in private schools.

Third, school buses, as a commonly accepted travel mode alternative, should be given sufficient attention. Two private schools in this study provide milk-run school bus services, and the corresponding uses in these two schools are very desirable and the mode shares are as high as $17.37 \%$ and $29.38 \%$, respectively. Regularly and officially operated school bus services could offer students a more convenient and safe travel option and attract a large number of students to take school buses rather than the parental car as the primary travel mode to school. Zhang et al. [38] pointed out that the school bus plan has not developed in China as mature as that in other countries. Cooperating with public bus companies, market-based shuttle bus services designated for school travels during the morning and afternoon hours are operating in some Chinese city cases. Gong and Zhang [32] reviewed its implementation effects in the case city of Jinhua. One valuable suggestion which could also be applied to other cities is to integrate this on-demand bus service with location-based applications. It not only could better serve pupils with demands, but also could enhance visibility for children's parents.

\section{Conclusion}

School travel is not only an important task for children's daily activities but also a major issue of everyday mobility organization for each student-owned household and even for education and transport authorities. Interstudent variations on school travel reflect whether schools could be equally accessed by each household. The inequities existing in travel duration, distance, and mode choice warrant attention as a matter of both scholarship and public policy. Insights into these inequities over different student segments facilitate mitigating travel inequities and promote the school mode shift to be more active [41].

With the case city of Shenzhen, this study illustrates how the residence-related hukou system gives birth to travel inequities between students from public and private schools. Students from disadvantaged families who do not have full residence rights have been excluded by the current public school system. Moreover, these disadvantaged students have lower accessibility to private primary schools. Relative deprivation of accessibility to school possibly results in more constraints on travel mode flexibility, longer travel distance, and time consumption.

Regarding travel mode, although student age and gender are closely associated with travel mode choices, the most significant factors leading to motorized travel are the trip length and the availability of household vehicles. A longer distance from home to school increases the likelihood of 
using motorized travel, and parents with private cars are likely to take children to school. The contextual built environment could play a somewhat important role but its role could be rationally recognized. Enhancing the surrounding of private schools located in peripheral areas could obtain more desirable expectations of promoting mode shift to active travels.

Due to the unavailability of supportive data, the number of sample schools was limited. More schools distributed in the whole metropolitan were not included in this study, and more explanatory variables should be considered by the empirical models. These deficiencies limit mining more associations to illustrate school travel inequities from multiple aspects. In addition, the interaction between households and school travel also has not been adequately addressed in this study. All these issues imply future research directions. However, the overall objective of this study has been fulfilled which is to recognize the school travel inequities among groups and attempts to equalize the variations with group-specific strategies.

\section{Data Availability}

The transport research data used to support the findings of this study are available from the corresponding author upon request.

\section{Conflicts of Interest}

The authors declare that they have no conflicts of interest.

\section{References}

[1] E. Andersson, B. Malmberg, and J. Östh, "Travel-to-school distances in Sweden 2000-2006: changing school geography with equality implications," Journal of Transport Geography, vol. 23, pp. 35-43, 2012.

[2] S. Easton and E. Ferrari, "Children's travel to school-the interaction of individual, neighbourhood and school factors," Transport Policy, vol. 44, pp. 9-18, 2015.

[3] B. P. Y. Loo and W. W. Y. Lam, "Does neighbourhood count in affecting children's journeys to schools?" Children's Geographies, vol. 13, no. 1, pp. 89-113, 2015.

[4] C. G. Pooley, J. Turnbull, and M. Adams, "The journey to school in Britain since the 1940s: continuity and change," Area, vol. 37, no. 1, pp. 43-53, 2005.

[5] M. Stone, K. Larsen, G. E. J. Faulkner, R. N. Buliung, K. P. Arbour Nicitopoulous, and J. Lay, "Predictors of driving among families living within $2 \mathrm{~km}$ from school: exploring the role of the built environment," Transport Policy, vol. 33, pp. 8-16, 2014.

[6] H. P. Van der Ploeg, D. Merom, G. Corpuz, and A. E. Bauman, "Trends in Australian children traveling to school 1971-2003: burning petrol or carbohydrates?" Preventive Medicine, vol. 46, no. 1, pp. 60-62, 2008.

[7] A. Broberg and S. Sarjala, "School travel mode choice and the characteristics of the urban built environment: the case of Helsinki, Finland," Transport Policy, vol. 37, pp. 1-10, 2015.

[8] J. V. Loon and L. Frank, "Urban form relationships with youth physical activity: implications for research and practice," Journal of Planning Literature, vol. 26, no. 3, pp. 280-308, 2011.
[9] N. C. McDonald, "Is there a gender gap in school travel? An examination of US children and adolescents," Journal of Transport Geography, vol. 20, no. 1, pp. 80-86, 2012.

[10] N. Singh and V. Vasudevan, "Understanding school trip mode choice-The case of Kanpur (India)," Journal of Transport Geography, vol. 66, pp. 283-290, 2018.

[11] R. L. Mackett, "Children's travel behaviour and its health implications," Transport Policy, vol. 26, pp. 66-72, 2013.

[12] E. J. Wilson, R. Wilson, and K. J. Krizek, "The implications of school choice on travel behavior and environmental emissions," Transportation Research Part D, vol. 12, no. 7, pp. 506-518, 2007.

[13] S. Li and P. Zhao, "The determinants of commuting mode choice among school children in Beijing," Journal of Transport Geography, vol. 46, pp. 112-121, 2015.

[14] L. F. Beck and D. D. Nguyen, "School transportation mode, by distance between home and school, United States, Consumer Styles 2012," Journal of Safety Research, vol. 62, pp. 245-251, 2017.

[15] A. Medeiros, A. Buttazzoni, S. E. Coen, A. F. Clark, K. Wilson, and J. Gililand, "Review of gender, socioeconomic status, and ethnic background considerations reported in," Active School Travel Intervention Studies, vol. 21, Article ID 101035, 2021.

[16] A. Guliani, R. Mitra, R. N. Buliung, K. Larsen, and G. Faulkner, "Gender-based differences in school travel mode choice behavior: examining the relationship between the neighborhood environment and perceived traffic safety," Journal of Transport and Health, vol. 2, no. 4, pp. 502-511, 2015.

[17] A. I. Moreno-Monroy, R. Lovelace, and F. R. Ramos, "Public transport and school location impacts on educational inequalities: insights from São Paulo," Journal of Transport Geography, vol. 67, pp. 110-118, 2018.

[18] N. McDonald, S. Librera, and E. Deakin, "Free transit for lowincome youth: experience in san francisco bay area, California. Transportation research record," Journal of the Transportation Research Board, vol. 1887, pp. 153-160, 2004.

[19] R. Zhang, E. Yao, and Z. Liu, "School travel mode choice in Beijing, China," Journal of Transport Geography, vol. 62, pp. 98-110, 2017.

[20] C. Clotfelter, "School desegregation, "tipping," and private school enrollment," Journal of Human Resources, vol. 11, pp. 28-50, 1976.

[21] K. Arbour-Nicitopoulos, G. E. J. Faulkner, R. N. Buliung, J. Lay, and M. Stone, "The school run: exploring carpooling as an intervention option in the Greater Toronto and Hamilton Area (GTHA), Canada," Transport Policy, vol. 21, pp. 134-140, 2012.

[22] R. Mitra and R. N. Buliung, "Exploring differences in school travel mode choice behaviour between children and youth," Transport Policy, vol. 42, pp. 4-11, 2015.

[23] R. Mitra and R. N. Buliung, "The influence of neighborhood environment and household travel interactions on school travel behavior: an exploration using geographically-weighted models," Journal of Transport Geography, vol. 36, pp. 69-78, 2014.

[24] S. Müller, S. Tscharaktschiew, and K. Haase, "Travel-to-school mode choice modelling and patterns of school choice in urban areas," Journal of Transport Geography, vol. 16, no. 5, pp. 342-357, 2008.

[25] J. Stark, I. B. Bartana, A. Fritz, W. Unbehaun, and R. Hossinger, "The influence of external factors on children's travel mode: a comparison of school trips and non-school 
trips," Journal of Transport Geography, vol. 68, pp. 55-66, 2018.

[26] W. Elias and R. Katoshevski-Cavari, "The role of socio-economic and environmental characteristics in school-commuting behavior: a comparative study of Jewish and Arab children in Israel," Transport Policy, vol. 32, pp. 79-87, 2014.

[27] C. R. Emond and S. L. Handy, "Factors associated with bicycling to high school: insights from Davis, CA," Journal of Transport Geography, vol. 20, no. 1, pp. 71-79, 2012.

[28] C. Fusco, F. Moola, G. Faulkner, R. Buliung, and V. Richichi, "Toward an understanding of children's perceptions of their transport geographies: (non) active school travel and visual representations of the built environment," Journal of Transport Geography, vol. 20, no. 1, pp. 62-70, 2012.

[29] G. Mammen, M. R. Stone, R. Buliung, and G. Faulkner, "School travel planning in Canada: identifying child, family, and school-level characteristics associated with travel mode shift from driving to active school travel," Journal of Transport \& Health, vol. 1, no. 4, pp. 288-294, 2014.

[30] T. E. McMillan, "The relative influence of urban form on a child's travel mode to school," Transportation Research Part A: Policy and Practice, vol. 41, no. 1, pp. 69-79, 2007.

[31] C. Curtis, C. Babb, and D. Olaru, "Built environment and children's travel to school," Transport Policy, vol. 42, pp. 21-33, 2015.

[32] X. Liu, T. Lin, and Z. Li, "Analysis on school travel characteristics and trip generation rate in Shenzhen Primary and Secondary Schools," Road Traffic and Safety, vol. 15, no. 4, pp. 28-43, 2015.

[33] D. Gong and J. Zhang, "Specialized student shuttle bus for pupils from outside the school district: a case study of huancheng primary school in jinhua, zhejiang province," Urban Transport of China, vol. 18, no. 2, pp. 46-57, 2020, (in Chinese).

[34] J. A. Kelly and M. Fu, "Sustainable school commuting-understanding choices and identifying opportunities: a case study in Dublin, Ireland," Journal of Transport Geography, vol. 34, pp. 221-230, 2014.

[35] D. Pojani and K. Boussauw, "Keep the children walking: active school travel in Tirana, Albania," Journal of Transport Geography, vol. 38, pp. 55-65, 2014.

[36] C. D. Van Goeverden and E. De Boer, "School travel behaviour in The Netherlands and Flanders," Transport Policy, vol. 26, pp. 73-84, 2013.

[37] E. Andersson, J. Östh, and B. Malmberg, "Ethnic segregation and performance inequality in the Swedish school system: a regional perspective," Environment and Planning A: Economy and Space, vol. 42, no. 11, pp. 2674-2686, 2010.

[38] R. Zhang, L. Lin, and J. Yang, "School- age children travel mode characteristics and affecting factors," Urban Transport of China, vol. 12, no. 2, pp. 78-83, 2014.

[39] J. F. Sallis, D. J. Slymen, T. L. Conway et al., "Income disparities in perceived neighborhood built and social environment attributes," Health and Place, vol. 17, pp. 1274-1283, 2011.

[40] X. Zhu and C. Lee, "Walkability and safety around elementary schools," American Journal of Preventive Medicine, vol. 34, pp. 282-290, 2008.

[41] J. Veitch, A. Carver, J. Salmon et al., "What predicts children's active transport and independent mobility in disadvantaged neighborhoods?" Health and Place, vol. 44, pp. 103-109, 2017. 